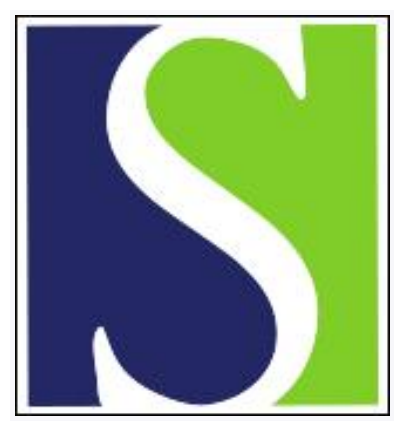

Scand J Work Environ Health 1988;14(3):161-167

https://doi.org/10.5271/sjweh.1936

Issue date: Jun 1988

Use of plant- and period-specific job-exposure matrices in studies on occupational cancer.

by Kauppinen T, Partanen $T$

Affiliation: Institute of Occupational Health, Helsinki, Finland.

This article in PubMed: www.ncbi.nlm.nih.gov/pubmed/3393851 


\title{
Use of plant- and period-specific job-exposure matrices in studies on occupational cancer
}

\author{
Timo Kauppinen, PhD, Timo Partanen, MSc, MPh ${ }^{1}$
}

\begin{abstract}
KAUPPINEN T, PARTANEN T. Use of plant- and period-specific job-exposure matrices in studies on occupational cancer. Scand J Work Environ Health 14 (1988) 161-167. Job-exposure matrices were constructed and applied in the estimation of past exposures in a case-referent study nested within a cohort of Finnish woodworkers. The objective was to avoid bias in the risk estimates because of a misclassification of exposures. The matrices were constructed separately for each plant under study and each calendar year of follow-up. The level of exposure was incorporated in the matrices, since rather comprehensive data on exposures were available. The individual work histories were converted to exposure histories by a computer program which calculated several exposure indicators (eg, level and dose, with and without allowance for a latency period). The comparison between several indicators was thought to provide additional information for the final evaluation of results. The use of the plant- and period-specific job exposure matrices may be considered in cohort and nested case-referent studies on occupational hazards as an alternative to other procedures used in the estimation of exposures. Specific matrices may find broader applicability along with the increasing availability of detailed hygienic data.
\end{abstract}

Key terms: epidemiology, exposure assessment, formaldehyde, wood industry.

A job-exposure matrix may be defined as a crossclassification of a list of job titles with a list of agents to which persons carrying out the jobs may be exposed (1). The elements of the matrix indicate the presence or absence of exposure within each job title, but additional elements may be incorporated, eg, indicators of the proportion of exposed persons and the level of exposure. The number and definition of the exposures and job titles vary across different job-exposure matrices. A matrix may be called a general job-exposure matrix if it covers all job titles in a nationwide classification of occupations. A specific matrix is restricted to a selected subset of job titles.

Early cross-tabulations resembling job-exposure matrices can be traced back to the 1940s. The first general job-exposure matrix was reported in the United States in 1980 (13). The "job axis" of this matrix covers all industries and occupations, and the "exposure axis" incorporates 376 chemical agents. The second matrix covering the whole range of industries and occupations was published in the United Kingdom in 1986 (18). It includes 50 chemical, physical, or other potential risk factors on its exposure axis. In addition to these comprehensive matrices, two more-limited matrices based on data from epidemiologic studies have been constructed in Italy (16). One includes exposure to eight lung carcinogens, and the other exposure to 74 chemicals possibly associated with bladder cancer.

Similar computerized data sets covering a wide range of occupations and exposures are probably available

\footnotetext{
1 Institute of Occupational Health, Helsinki, Finland.
}

Reprint requests to: Dr T Kauppinen, International Agency for Research on Cancer (IARC), 150 Cours Albert-Thomas, 69372 Lyon Cedex 08, France. also in other countries even though they have not been constructed in the form of a matrix. Examples of these are the Canadian data based on interviews of cancer patients in a large case-referent study, into which 275 (initially 172) chemical agents have been incorporated (10), and the Finnish register of employees occupationally exposed to 162 (initially 50 ) carcinogens (3).

The main function of a job-exposure matrix is to provide information about the connections between exposures and diseases through the linkage of the job titles with the exposures in a systematic, unbiased way. Job-exposure matrices can be used as a research tool in the generation, and sometimes in the testing, of hypotheses in register-based or other epidemiologic studies. They may also be used as an instrument of preventive action because they include information about the occupational groups exposed to known hazardous agents.

One of the main problems of job-exposure matrices is the misclassification of exposures, which introduces bias - in many cases a negative one - in the measures of occurrence relation (5). The source of misclassification may be incomplete specificity or sensitivity of the exposure assessment, or both. Low specificity results particularly when the job title classes are broad and a considerable number of the workers classified as exposed is in fact unexposed to the agent because of job-, time-, or plant-specific factors. The omission of a latency period may also lead to loss of specificity, as recent exposures will be recorded as exposures - even though their importance in the initiation of the observed cancers may be limited. Low sensitivity results if exposures remain unidentified in the matrix. If complete occupational histories of the subjects are not taken into account, some jobs - and consequently 
exposures - may be missed, and the sensitivity of exposure assessment is reduced. The problems involved in the misclassification of exposures in epidemiologic studies have been treated in several articles $(6,8,11$, $12,17,24)$.

The present article describes an application of jobexposure matrices in a case-referent study on respiratory cancer nested within a cohort of woodworkers. For the purpose of increasing sensitivity and specificity, two additional dimensions, calendar time and plant, were incorporated into the matrices. A further goal was to reduce information bias by excluding the subjective elements in the determination of the $12 \mathrm{ex}-$ posures under study. A fairly similar procedure has been recently used also in the context of a cohort study among workers exposed to formaldehyde (22).

\section{Study design}

The respiratory cancers incident between 1957 through 1980 among a retrospective entry cohort of 3805 male workers in Finnish particleboard, plywood, and sawmill industries were identified. The admissibility criteria for the cohort were at least one year of work at the selected plants between 1944 and 1965 and year of birth 1900 or later. The list of eligible workers from 19 plants was linked with the data of the Finnish Cancer Register. Fifty-seven verified cases of respiratory cancer were identified. Three referents matched by year of birth were selected for each case from the cohort. The referents had to be alive at the time of the diagnosis of the corresponding case. The exposures of the cases and the referents were registered for formaldehyde, wood dust, chlorophenols, terpenes, pesticides, and some other exposures with the job-exposure matrix

Table 1. Classification of formaldehyde exposure.

\begin{tabular}{|c|c|}
\hline $\begin{array}{l}\text { Exposure } \\
\text { level }\end{array}$ & Definition of exposure level \\
\hline \multicolumn{2}{|c|}{ Formaldehyde } \\
\hline 0 & $\begin{array}{l}\text { Concentration in the workroom air below } 0.1 \\
\text { ppm or dose below } 3 \mathrm{ppm} \text {-months }\end{array}$ \\
\hline 1 & $\begin{array}{l}\text { Concentration in the workroom air } 0.1-1 \mathrm{ppm} \\
\text { and dose at least } 3 \mathrm{ppm} \text {-months }\end{array}$ \\
\hline 2 & $\begin{array}{l}\text { Concentration in the workroom air } 1-2 \mathrm{ppm} \\
\text { and dose at least } 3 \mathrm{ppm} \text {-months }\end{array}$ \\
\hline 3 & $\begin{array}{l}\text { Concentration in the workroom air over } 2 \mathrm{ppm} \\
\text { and dose at least } 3 \mathrm{ppm} \text {-months }\end{array}$ \\
\hline 9 & Indeterminate exposure \\
\hline \multicolumn{2}{|c|}{$\begin{array}{l}\text { Formaldehyde, } \\
\text { peak exposure }\end{array}$} \\
\hline $\begin{array}{l}0 \\
1 \\
9\end{array}$ & $\begin{array}{l}\text { No repeated exposures to peaks over } 2 \mathrm{ppm} \\
\text { Repeated exposures to peaks over } 2 \mathrm{ppm} \\
\text { Indeterminate exposure }\end{array}$ \\
\hline \multicolumn{2}{|c|}{$\begin{array}{l}\text { Formaldehyde, } \\
\text { attached to } \\
\text { wood dust }\end{array}$} \\
\hline 0 & $\begin{array}{l}\text { No wood dust containing formaldehyde glue } \\
\text { in the workroom air }\end{array}$ \\
\hline 1 & $\begin{array}{l}\text { Wood dust containing formaldehyde glue in } \\
\text { the workroom air }\end{array}$ \\
\hline 9 & Indeterminate exposure \\
\hline
\end{tabular}

technique described in this report. The results of the study have been published in detail elsewhere $(14,19)$.

\section{Construction of plant- and period-specific job-exposure matrices}

\section{Relevant exposures and their classification}

All common exposures in the industries under study were identified through a survey of chemicals used and through knowledge of the formation of some air contaminants in the manufacturing processes. Exposures to known or suspected carcinogens among the study population were assessed; these included exposure to formaldehyde, wood dust, chlorophenols, engine exhaust, and certain pesticides. Terpenes and other heating products of coniferous woods, phenol, caseinalbumin glues, melamine glues, and solvents were also included in the matrices. The exposure data for bis(chloromethyl)ether and biological air contaminants (eg, fungal spores) did not permit an accurate evaluation of exposure; they were therefore included in the matrix as potential exposures, assessed mainly by "educated guesses." The total number of exposures in the matrices thus became twelve.

An exact level- and dose-based definition of " $\mathrm{ex}$ posure" was judged necessary - especially for formaldehyde - in order to minimize the misclassification of exposure due to nonoccupational factors. For instance, the indoor air of dwellings may be an important source of exposure to formaldehyde. The minimum criterion of exposure to formaldehyde was therefore set at a dose of 3 ppm-months and a level of 0.1 ppm, on the basis of estimated exposure in dwellings. For the remaining compounds, one month of exposure at a level clearly exceeding the nonoccupational background level was required.

In addition to these criteria, further characteristics of exposure were incorporated into the construction of the exposure classifications. A separate indicator was assigned to agents attached to a "carrier," such as wood dust, because the carrier may affect the risk by changing the distribution of the chemical agent in the respiratory tract. An additional indicator was defined for the peak exposure to formaldehyde, because this may be a specific risk factor, as suggested by animal experiments in which a high risk of nasal cancer was found only for very high formaldehyde concentrations $(2,15)$. Subjects with uncertain exposures were excluded from the analysis in order to reduce the misclassification of exposures. The number of categories of exposure level was decided upon after an evaluation of the available industrial hygienic data. These data allowed the division of the exposure level for formaldehyde, wood dust, and chlorophenols into the category of nonexposure and three levels of exposure. For the remaining agents, one or two categories of exposure were considered sufficient. The classification of formaldehyde exposure is shown as an example in table 1 . 


\section{Relevant jobs and their classification}

The general occupational classifications available were not sufficiently detailed for the purposes of the study. Specific and sensitive determination of the exposures require that the occupational categories be internally homogeneous in regard to the exposures. The manufacturing processes of the industries under study were therefore divided into homogeneous "exposure zones" (7), and the job titles were matched to these zones. This procedure resulted in 73 job categories. Some mills were visited in order to insure that the old job titles were included and that the classification compared approximately with that in the mill records so that the occupational histories could be coded without difficulty according to the constructed classification system.

\section{Content of the job-exposure matrices}

After the basic dimensions of the matrices - the jobs and the exposures - had been defined, the next and the most laborious task was to fill in the "cells" of the matrices. Several sources of information were used. The results of previous hygienic measurements were collected from the mills and from the archives of the Finnish Institute of Occupational Health. The results were critically evaluated because the exposure data may become biased if, for example, the purpose of the measurements, the measuring methods used, the conditions during the measurements, or the sampling strategy are disregarded $(20,25)$. Current hygienic data were used in the estimation of the recent level of exposure and as an indication of the variability of exposures among different mills. A comparison of the present and past data also showed whether any prominent changes in the exposures had taken place over time.

Next, hygienic measurements were made for the jobs with missing or unreliable data. They were carried out in two plywood mills, one particleboard mill, and one sawmill. The preliminary job-exposure matrices were prepared on the basis of the total body of material provided by past and present measurements.

After the occupational histories of the cases and the referents had been collected, the preliminary matrices were checked at the mills. Only those job titles appearing in the occupational histories of the cases and the referents were checked. The case/referent status was blinded from the occupational hygienist (TK), who had only a list of jobs held by the cases and referents. The onset and possible termination of the exposures, the exposure levels, and the changes in the exposure levels over time were registered. The evaluation of the changes over time was based on factors considered to influence the exposures, such as changes in the raw materials used, chemicals used, ventilation, and use of respirators. Information was obtained mainly in interviews with senior foremen and older workers and
Table 2. Content of one element of a job-exposure matrix, ie, hot pressing in a plywood factory.

\begin{tabular}{lccccc}
\hline $\begin{array}{l}\text { Code } \\
\text { of } \\
\text { plant }\end{array}$ & $\begin{array}{c}\text { Code } \\
\text { of } \\
\text { job }\end{array}$ & $\begin{array}{c}\text { Code } \\
\text { of } \\
\text { exposure }\end{array}$ & $\begin{array}{c}\text { Start of } \\
\text { period } \\
\text { (month,year) }\end{array}$ & $\begin{array}{c}\text { End of } \\
\text { period } \\
\text { (month,year) }\end{array}$ & $\begin{array}{c}\text { Level } \\
\text { of } \\
\text { exposure }\end{array}$ \\
\hline 17 & 210 & 01 & 0755 & 1273 & 2 \\
& & 01 & 0174 & 0181 & 1 \\
& 02 & 0755 & 0181 & 1 \\
& 07 & 0767 & 0181 & 1 \\
& & 09 & 0760 & 0181 & 1 \\
& 11 & 0144 & 0657 & 1 \\
& 15 & 0771 & 0181 & 9 \\
& 17 & 0755 & 0181 & 1 \\
\hline
\end{tabular}
Exposures: $01=$ formaldehyde, $02=$ formaldehyde, peak exposure,
$07=$ pesticides, $09=$ phenol, $11=$ casein-albumin glues, $15=$ terpenes
and other heating products of coniferous woods, $17=$ engine exhaust,
$18=$ bis(chloromethyl)ether. No exposure to any other agent and no exposure during other periods.

from surveys of the mills. Histories of the mills, old layouts, and photographs were also used. An example of a checked matrix element is shown in table 2 .

The accuracy of the results does not depend only on the quality of the matrices, but on the occupational history data as well. These data were collected from three independent sources. First, the mill records often provided accurate information of the dates of entry and termination of employment of the worker in different occupations, but in many cases the descriptions of the jobs were not sufficiently accurate. Second, interviews of senior foremen and co-workers resulted in accurate descriptions of the jobs, but the dates were inaccurately recalled. Third, a questionnaire was mailed to the persons themselves (if alive) or to the next-of-kin. This information was used for reviewing the entire work history and for obtaining information on smoking habits. The occupational history was reconstructed as a combination of information from the three sources. Whenever contradictions between the different sources were indicated, the source likely to be the most reliable was chosen as the basis for the coding.

\section{Exposure indicators}

A computer program was constructed which linked the occupational histories (for the 19 target mills) with the plant- and period-specific matrices and calculated the exposure data for the cases and referents. The cases and referents were classified according to the level of exposure [eg, in parts per million (ppm)], duration of exposure (in years), and dose (product of the estimated level of exposure and duration of exposure, eg, in ppm-years). The calculated odds ratios were adjusted for the duration of tobacco smoking and the survival status. The computer program also allowed the use of a minimum criterion for the latency period in the calculations. This criterion was set at 10 years, but the calculations were also made without the latency period. Typical sets of results obtained with these procedures are shown in table 3 . 
Table 3. Odds ratio (OR) estimates and $90 \%$ confidence intervals $(90 \% \mathrm{Cl})$ for respiratory cancer according to different indicators of exposure to formaldehyde. All the odds ratios have been adjusted by stratification for survival status. Data from Partanen et al (19).

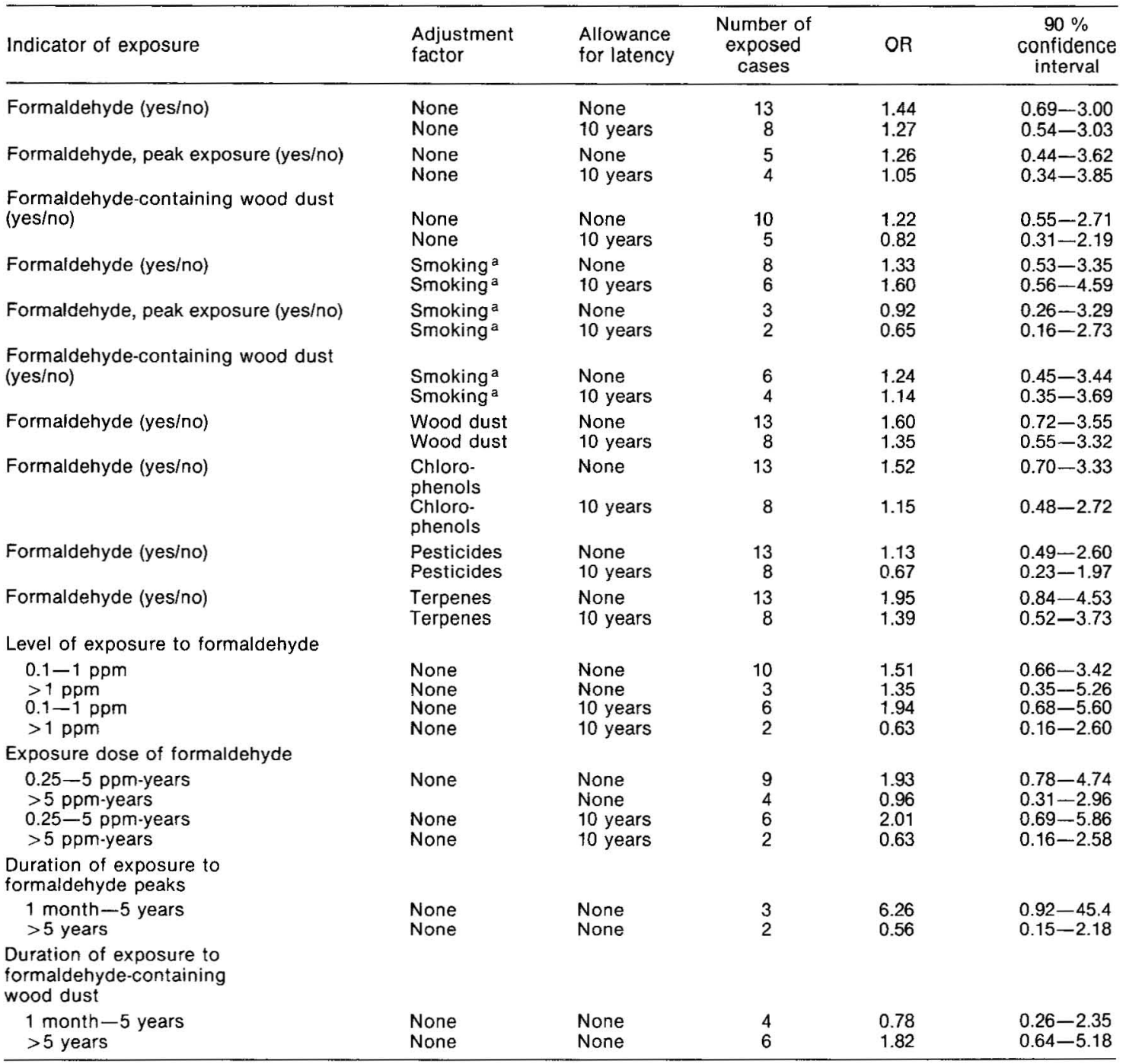

a Missing data on smoking accounts for a decreased number of exposed cases.

\section{Discussion}

The described procedure is an example of the way plant- and period-specific job-exposure matrices may be constructed and applied in an epidemiologic study. In regard to the applicability of the matrix approach, the nested case-referent design has some advantages over the traditional cohort and population-based casereferent designs. The important features of a valid jobexposure matrix - high specificity and sensitivity are casier to obtain with the nested case-referent design because only a fairly small number of plants, job titles, exposures, and occupational histories need to be considered. To be sure, this approach is applicable also in cohort studies because they are usually restricted to only one or a few exposures. However, the number of occupational histories to be collected and checked is often much higher than in a nested case-referent study, where only the occupational histories of the cases and referents have to be scrutinized. The population-based case-referent studies, on the other hand, have the disadvantage of embracing a wide spectrum of job titles and exposures. This circumstance forces the researcher to use rather general, nonspecific classifications of job titles and exposures in the matrix, which tends to increase the misclassification of exposures. In the nested case-referent design, high sensitivity and specificity of the matrices can be achieved if the matrices are constructed and checked for every plant and time period involved.

The main objective of the use of job-exposure matrices in the present study was to avoid the misclassification of exposures, which, even if nondifferential, 
may have a major effect on the risk estimates. This effect can be demonstrated by the following example.

Let us assume that the exposure indicator is coded in a binary fashion (no-yes) and, further, that misclassification of exposure is nondifferential, ie, the sensitivity and specificity of exposure assessment are independent on the case-referent status - a reasonable assumption for the present data, particularly if the analysis is done stratified according to the survival status, a likely source of nondifferential misclassification in this study.

In the simple general case of nondifferential misclassification in unstratified, unmatched data, the effect of incomplete sensitivity and specificity is bias towards the null value of the odds ratio. The magnitude of the bias depends not only on the sensitivity and specificity but also on the proportion of exposed persons in the base, estimated by a simple random sample of the base, ie, the referents.

In general, if only a low proportion of persons say, 0.05 or less - is exposed, even a minor deviance from perfect specificity (eg, from 1.00 to 0.95 ) results in a marked absolute bias toward the null value (figure 1 , left). The higher the proportion of the exposed, the greater the effect of sensitivity on the expected odds ratio, as illustrated in figure 1 (right), in which $50 \%$ of the referents is assumed to be exposed and the sensitivity of the exposure assessment is set at 0.9 . On the assumption of perfect specificity, a correct expected odds ratio of 6 will, in this case, be biased into the value of slightly higher than 4 . Loss in specificity further in- creases the bias, although not so drastically as loss in sensitivity. For any fixed values of specificity, sensitivity, and proportion of exposed persons, the absolute bias increases as the odds ratio increases.

We back-calculated a few odds ratios derived from our data so as to correct for incomplete sensitivity and specificity of exposure assessment. The data was stratified by survival status (alive/deceased). The adjusted odds ratios were then calculated with Gart's procedure (9). We assumed sensitivities and specificities to be between 0.8 and 1 , depending on the exposure variate and survival status. For the uncorrected odds ratios between 1 and 1.5 , only very minor changes took place, as expected. The greatest absolute change was in the odds ratio for formaldehyde with the provision for a 10 -year latency period. On the assumption of a sensitivity of exposure assessment of 0.9 for the living and 0.8 for the deceased and a specificity of 0.95 for both, the original adjusted odds ratio increased from 1.44 to 1.56 after correction.

In the present study, the job-exposure matrix technique probably diminished differential misclassification by excluding subjective elements in the evaluation of exposures. However, the following indications of a negative bias were observed in the preliminary analysis of the data: the exposure-response relationships were often negative (the odds ratio for low exposure was higher than that for high exposure); some odds ratios were below unity; and the provision for a latency period decreased many odds ratios. The most likely reason for these anomalies appeared to be the under-
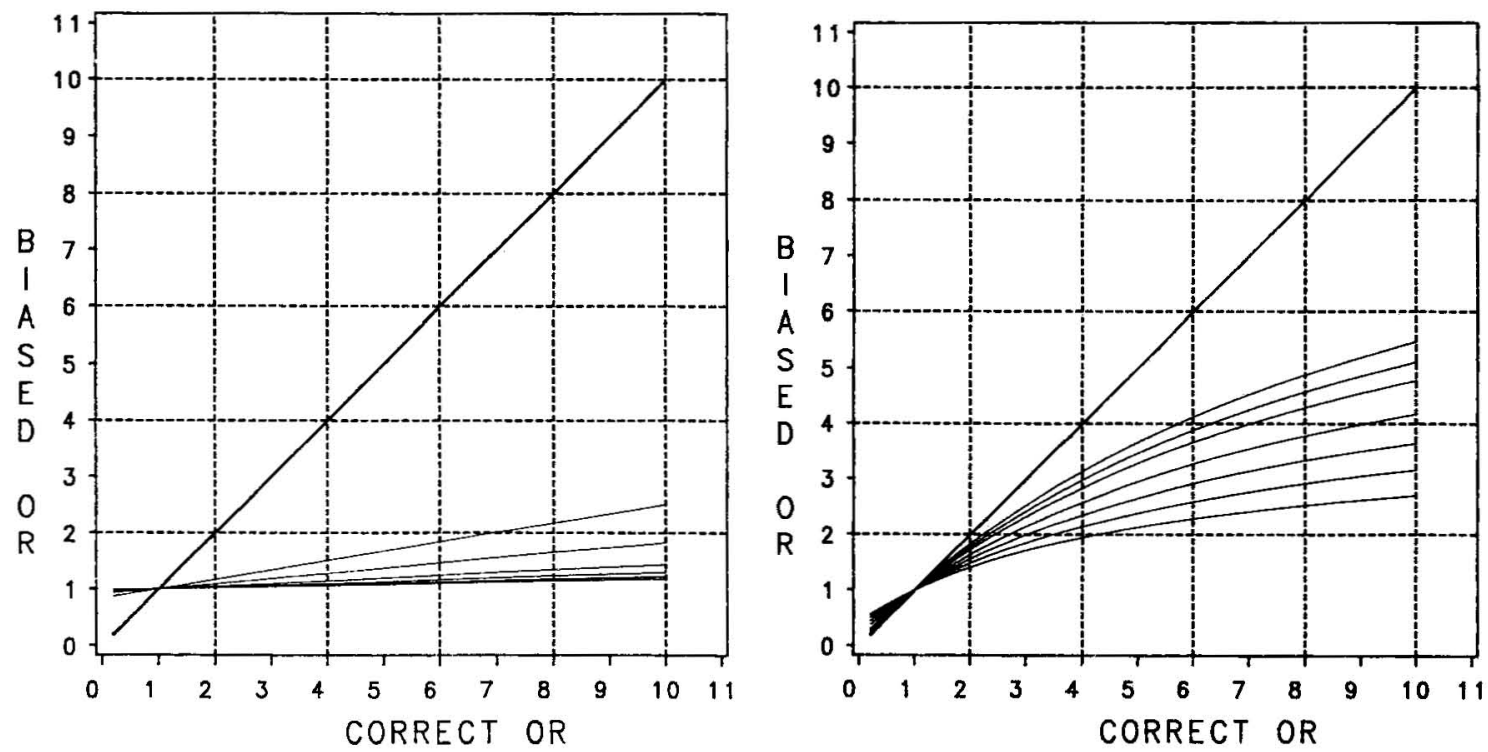

Figure 1. Effect of a nondifferential misclassification of exposure (coded no-yes) on the expected odds ratio (OR) in a casereferent study, as a function of the true proportion of exposed persons $(P(E))$ among the referents, sensitivity (Se $=$ proportion of false negative exposures), and specificity ( $\mathrm{Sp}=$ proportion of false positive exposures). $P(E)=0.01$ (left), 0.5 (right); Se $=1$ (left), 0.9 (right); diagonal line: unbiased $\mathrm{OR}(\mathrm{Se}=1, \mathrm{Sp}=1$ ); curves up to down: $\mathrm{Sp}=1,0.95,0.9,0.8,0.7,0.6$, and 0.5 . In the figure on the left, the graph for $S p=1$ coincides with the diagonal line. 
reporting of job tasks (consequently also underreporting of exposures) among the cases. This bias is however not related to the job-exposure matrix technique; it is a consequence of asymmetry in the accuracy of occupational histories. The study design did not include matching by survival status; the proportion of living subjects was therefore higher among the referents $(67 \%)$ than among the cases $(5 \%)$. This asymmetry led to a number of incomplete occupational histories, especially among the "old" cases. Negative exposureresponse relationships were to a large extent explained by the fact that remote exposures were often heavier than recent ones. This type of information bias can be corrected either by stratifying the data by survival status (as was done in the present study) or by matching the survival status in the study design phase.

The likelihood of a nondifferential misclassification of exposures will also probably remain low if the plantand period-specific job-exposure matrices are constructed on the basis of jobs homogeneous in regard to exposures. However, should there still remain heterogeneity within some job categories, misclassification would result. A source of such misclassification is the possibility that some workers doing the same work in the same work area are not exposed because of their regular use of effective respirators. In that case, also the use of respirators should be incorporated in the construction of the job categories.

Another possible source of misclassification is the use of partial occupational histories. Complete occupational histories were elicited in the present study by a postal questionnaire, but jobs held outside the studied mills by the cases and referents were not used in the data analysis because it was too laborious to ascertain all possible exposures from the numerous workplaces reported. Partial omission of the occupational histories may thus have been a source of misclassification of exposure, but this bias was unlikely because additional (omitted) exposures to the studied chemical agents were evaluated, on the basis of the occupational histories collected, as being infrequent and rather evenly distributed among the cases and referents. However, some dose estimates (eg, for wood dust) may have been underestimated or inaccurate and, if so, would tend to level off exposure-response relationships (4).

Reliable methods of exposure assessment based on homogeneous exposure zones and a high quality of occupational histories are important prerequisites of a valid estimation of exposures. However, there is an additional problem to be considered in epidemiologic studies, ie, the choice among various indicators of exposure. An indicator which accurately measures the exposure of the target organ to the chemical agent under study and which includes adjustment for the latency period required is likely to be relevant. For formaldehyde, the most sensitive indicator might well be the estimated dose, with provision for a latency period. However, it may also be argued that some other indicator, for example, the duration of peak exposure with provision for a latency period, is preferable. The use of indicators which do not include the time dimension (eg, the mean level of exposure) has also been preferred over indicators including time (eg, dose, duration of exposure) because the latter may lead to artificial similarity of exposures among the cases and referents. This bias is likely to appear when the design is matched by several time-dependent factors, such as year of birth, year of beginning employment, and duration of employment (21).

Another problem in the choice of exposure indicators appears to be how to "weight" temporal factors, such as remote and recent exposures, the time since the termination of exposure, and the age of the person during exposure. Moreover, the answers to these questions are likely to depend on the type of cancer and on the physicochemical and toxicologic properties of the exposures. (See, eg, reference 23.) Nevertheless, the approach of the present study was to construct several exposure indicators instead of just one. This approach provides information about different aspects of cancer risk, such as the exposure-response relationship and latency dependence, which can then be used for the evaluation of the plausibility of occupational exposures as etiologic factors.

In conclusion, plant- and period-specific jobexposure matrices based on homogeneous exposure zones may be recommended for consideration in nested case-referent and cohort studies on occupational hazards as an alternative to the other procedures used in the estimation of exposures. The matrices of the type used in this study are likely to decrease misclassification, particularly differential misclassification, of exposures. The described procedure also allows for the calculation and comparison of several indicators of exposure which may contribute to the assessment of the credibility of the findings. In the future, when more hygienic data will be available for epidemiologic studies and when smaller risks and risks confounded by multiple exposures will probably be studied to an increasing extent, this procedure may be a useful model to follow.

\section{Acknowledgments}

We gratefully acknowledge the help provided by $\mathrm{P}$ Mutanen, MSc, a systems analyst at the Finnish Institute of Occupational Health, who programmed the calculations concerning the effects of misclassification on the expected odds ratios.

\section{References}

1. Acheson ED. What are job exposure matrices? In: Med ical Research Council, Environmental Epidemiology Unit. Job exposure matrices: Proceedings of a conference held in April 1982 at the University of Southampton. Southampton 1983, pp 1-4. (Scientific report no 2). 
2. Albert RE, Sellakumar AR, Laskin S, Kuschner M, Nelson N, Snyder CA. Gaseous formaldehyde and hydrogen chloride induction of nasal cancer in the rat. $\mathbf{J}$ Nat Cancer Inst 68 (1982) 597-603.

3. Alho J, Kauppinen T, Sundquist E. Use of exposure registration in the prevention of occupational cancer in Finland. Am J Ind Med (in press).

4. Armstrong BG, Oakes D. Effects of approximation in exposure assessments on estimates of exposure-response relationships. Scand J Work Environ Health 8 (1982): suppl 1, 20-23.

5. Bross I. Misclassification in $2 \times 2$ tables. Biometrics 10 (1954) 478-486.

6. Copeland KT, Checkoway H, McMichael AJ, Holbrook $\mathrm{RH}$. Bias due to misclassification in the estimation of relative risk. Am J Epidemiol 105 (1977) 488-495.

7. Corn M, Esmen NA. Workplace exposure zones for classification of employee exposures to physical and chemical agents. Am Ind Hyg Assoc J 40 (1979) 47-57.

8. Flegal KM, Cavell B, Haas JD. The effect of exposure misclassification on estimates of relative risk. Am J Epidemiol 123 (1986) 736-751.

9. Gart JJ. The comparison of proportions: A review of significance tests, confidence intervals and adjustments for stratification. Rev Int Stat Inst 39 (1971) 148-169.

10. Gérin M, Siemiatycki J, Kemper H, Bégin D. Obtaining occupational exposure histories in epidemiologic case-control studies. J Occup Med 27 (1985) 420-426.

11. Greenland $S$. The effect of misclassification in the presence of covariates. Am J Epidemiol 112 (1980) 564569.

12. Greenland $\mathrm{S}$. The effect of misclassification in matchedpair case-control studies. Am J Epidemiol 116 (1982) $402-406$.

13. Hoar SK, Morrison AS, Cole P, Silverman DT. An occupation and exposure linkage system for the study of occupational carcinogenesis. J Occup Med 22 (1980) $722-726$.

14. Kauppinen T, Partanen T, Nurminen M, Nickels J, Hernberg S, Hakulinen T, Pukkala E, Savonen E. Respiratory cancers and chemical exposures in the wood industry: A nested case-control study. $\mathrm{Br} \mathrm{J}$ Ind Med 43 (1986) 84-90.

15. Kerns WD, Pavkov KL, Donofrio DJ, Gralla EJ, Swenberg JA. Carcinogenicity of formaldehyde in rats and mice after long-term inhalation exposure. Cancer Res 43 (1983) 4382-4392.

16. Macaluso M, Vineis P, Continenz D, Ferrario F, Pisa- ni P, Andisio R. Job exposure matrices: Experience in Italy. In: Medical Research Council, Environmental Epidemiology Unit. Job exposure matrices: Proceedings of a conference held in April 1982 at the University of Southampton. Southampton 1983, pp 22-30. (Scientific report no 2).

17. Marshall JR, Priore R, Graham S, Brasure J. On the distortion of risk estimates in multiple exposure level case-control studies. Am J Epidemiol 113 (1981) 464473.

18. Pannett B, Coggon D, Acheson ED. A job-exposure matrix for use in population based studies in England and Wales. Br J Ind Med 42 (1985) 777-783.

19. Partanen $T$, Kauppinen $T$, Nurminen M, Nickels $J$, Hernberg S, Hakulinen T, Pukkala E, Savonen E. Formaldehyde exposure and respiratory and related cancers: A case-referent study among Finnish woodworkers. Scand J Work Environ Health 11 (1985) 409-415.

20. Sanderson J. Characterising exposure, past, present and future. In: Medical Research Council, Environmental Epidemiology Unit. Job exposure matrices: Proceedings of a conference held in April 1982 at the University of Southampton. Southampton 1983, pp 10-14. (Scientific report no 2).

21. Soskolne CL, Zeighami EA. Exposure measures and the potential for over-matching in occupational cancer casereferent studies. Scand J Work Environ Health 9 (1983) 57.

22. Stewart PA, Blair A, Cubit DA, Bales RE, Kaplan SA, Ward J, Gaffey W, O'Berg MT, Walrath J. Estimating historical exposures to formaldehyde in a retrospective mortality study. Appl Ind Hyg 1 (1986) 34-41.

23. Thomas DC. Statistical methods for analyzing effects of temporal patterns of exposure on cancer risks. Scand J Work Environ Health 9 (1983) 353-366.

24. Tockman MS. Epidemiology in the workplace: The problem of misclassification. J Occup Med 24 (1982) $21-24$.

25. Ulfvarsson U. Användbarheten av luftföroreningsdata från arbetsplatser för bedömning av exponering i samband med yrkeshygieniska och epidemiologiska studier. [Use of air contaminant data from work places in exposure assessment in occupational hygienic and epidemiologic studies]. Arbetarskyddsverket, Stockholm 1983. (Arbete och hälsa 1983: 11).

Received for publication: 20 November 1987 